\title{
MENDESAIN KARAKTER SUNAN GUNUNG JATI SEBAGAI TOKOH SEJARAH DI KESULTANAN BANTEN DALAM BUKU ILUSTRASI
}

\author{
Nisa Sugiarti, Santi Sidhartani \\ Program Studi Desain Komunikasi Visual \\ Fakultas Bahasa Dan Seni, Universitas Indraprasta PGRI \\ Jl. Nangka 58 Tanjung Barat, Jakarta Selatan, 12530 \\ nisasugiart@gmail.com
}

\begin{abstract}
Abstrak
Studi ini ingin menjelaskan mengenai sultan Banten dalam memimpin kerajaannya hingga memperoleh masa keemasannya. Sunan Gunung Jati atau Sultan Syarif Hidayatullah adalah orang pertama yang mengislamkan Banten pada 1525. Sebagai sosok yang berpengaruh besar dalam memperluas kekuasaan Islam Demak. Sunan Gunung Jati dapat direpresentasikan secara visual dalam buku ilustrasi. Untuk membawa pesan tentang sosok yang menyebarkan Islam di tanah Banten. Metode penelitian yang digunakan dalam penulisan ini adalah penelitian kualitatif. Studi ini menjelaskan tentang penciptaan karakter tokoh Sunan Gunung Jati untuk buku ilustrasi, terutama dalam desain wajah, dan postur. Hasil desain karakter ini diharapkan dapat memberi gambaran tentang tokoh sejarah di Kesultanan Banten bagi anak-anak.
\end{abstract}

Kata kunci: Karakter, Sunan Gunung Jati, Kesultanan Banten

\begin{abstract}
Abstrack
This research want to explain about the sultan of Banten in leading the kingdom until get the prosperity. Sunan Gunung Jati or Sultan Syarif Hidayatullah is first person who Islamize Banten.in 1525. As the great influence in expanding the power of Demak Kindom. Sunan Gunung Jati can be representated as visual in illustration book. To bring a message about the figure who spread Islam in the land of Banten. The research method used in this writing is qualitative research. This study want to explain about making figure character Sunan Gunung Jati for illustration book, specially in the face and posture. The design result are expected to give a picture of historical figure in the Sultanate of Banten for children.
\end{abstract}

Keywords: Character, Sunan Gunung Jati, Banten Sultanate

\section{PENDAHULUAN}

Pada awalnya Banten adalah bagian dari Kerajaan Sunda. Namun, pada 1525 Syarif Hidayatullah berhasil menaklukan kerajaan tersebut atas utusan Sultan Trenggono. Tujuan penaklukan tersebut bukan hanya untuk memperluas wilayah Kerajaan Demak tetapi juga untuk menyebarkan agama Islam di Pulau Jawa (Guillot, 2008: 15).

Achmad (2017: 58), mengatakan bahwa, Syarif Hidayatullah merupakan putra Syarif Abdullah Umdatuddin yang berasal dari Palestina tersebut mengembangkan Cirebon sebagai pusat dakwah dan pemerintahan. Putranya yang bernama Maulana Hasanuddin berhasil mengembangkan kekuasaan dan menyebarkan agama Islam di Banten.

Syarif Hidayatullah pada 1525 berhasil mengislamkan wilayah Banten yang dahulunya masih daerah kekuasan Sunda Pajajaran. Kemudian, menyiarkan agama Islam dan 
memerintahkan anaknya, Maulana Hasanuddin untuk membangun istana di Banten. Pada 1527, Syarif Hidayatullah meinggalkan Banten dan pindah ke Cirebon untuk meminmpin dan menyebarkan Islam di sana hingga wafat. Syarif Hidayatullah di makamkan di bukit Cirebon yang orang menamakanya Gunung Jati yang membuatnya lebih dikenal dengan nama Sunan Gunung Jati (Graaf, 1989: 138).

Sebagai tokoh yang berpengaruh dalam berdirinya kerajaan Islam di Banten, tentunya Sunan Gunung Jati perlu direpresentasikan sosoknya secara visual melalui media berupa buku ilustrasi. Agar bisa memberikan gambaran mengenai karakter dari Sunan Gunung Jati. Buku ilustrasi adalah bacaan yang di dalamnya berisik teks dan juga gambar, seperti ilustrasi berbentuk sketsa, lukis, grafis, karikatur, dan sebagainya. Anggaraini dan Nathalia (2016: 32), unsur penting dalam buku ilustrasi di antaranya garis, warna, grid, tipografi, tata letak, dan ilustrasi. Dalam ilustrasi salah satunya terdapat penciptaan karakter tokoh.

Proses perancangan karakter tokoh Sunan Gunung Jati didasarkan pada tokoh historis, proporsi tubuh manusia pada jamannya, melihat dari film yang pernah dibuat sebelumnya dengan memerankan tokoh tersebut. Seiring berjalannya waktu, informasi tentang sejarah dalam bentuk buku ilustrasi diperlukan untuk mendorong ketertarikan anak-anak dalam mengenal sejarah dan tokoh yang terlibat di dalamnya.

Studi ini berupaya untuk merancang karakter tokoh Sunan Gunung Jati untuk mengenalkan karakter Sunan Gunung Jati. Menjelaskan secara visual dari karakter tersebut untuk mendalami sejarah mengenai Kesultanan Banten. Menjelaskan kejayaan Kesultanan Banten oleh beberapa pemimpin kesultanan, salah satunya Sunan Gunung Jati dengan merepresentasikan visual dari tokoh yang akan dibuat, terutama dalam bentuk wajah, postur tubuh, dan warna atau aksesoris yang dikenakan.

\section{METODE PENELITIAN}

Dalam penelitian ini, penulis menggunakan penelitian jenis kualitatif dengan teknik pengumpulan data studi pustaka, observasi, dan wawancara. Untuk merancang karakter Sunan Gunung Jati tersebut, peneliti melakukan kunjungan ke Museum Kepurbakalaan Banten, di Kecamatan Kasemen, Kota Serang, Provinsi Banten untuk mengumpulkan data-data pelengkap tentang benda atau alat-alat yang dipakai Banten tempo dulu, seperti pakaian, senjata, pekakas rumah, dan lainnya.

\section{PEMBAHASAN}

Desain karakter dapat dibangun melalui elemen desain, yaitu garis, bentuk, tekstur, dan warna. Semua itu akan membentuk kepribadian atau karakter, emosi, ekspresi, dan mewakili identitas, seperti jenis kelamin, kelas sosial, dan budaya (Pratama, dkk., 2018). Elemen visual bentuk juga dapat menentukan karakter. Bentuk tidak hanya bisa menghasilkan karakteristik penampilan, tetapi juga tipe kepribadiannya. Selanjutnya, ada elemen desain tekstur untuk melengkapi penciptaan karakter dalam buku ilustrasi, berupa tekstur lihat, yaitu permukaan yang bisa dirasakan dengan dilihat sebagai tekstur pseudeo karena sifatnya yang merupakan hasil dari gambar 2D, menurut Irawan dan Tamara (dalam Pratama, dkk., 2018).

Dari hasil observasi, Sunan Gunung Jati yang sederhana dan merakyat, serta saat dia mengislamkan Banten pada tahun 1525. Sunan Gunung Jati adalah seorang penyiar agama Islam yang telah lama tinggal di Mekah, dengan ciri khas pakaian langsung atau gamis, ciri-ciri inilah yang divisualisaikan dalam penciptaan karakter Sunan Gunung Jati.

Penciptaan karakter dapat membantu memberi gambaran tetang tokoh sejarah, khususnya sebagai media edukasi di sekolah. Syukur (dalam Anto, dkk., 2017), mengemukakan bahwa media pendidikan merupakan alat sebagai perantara untuk memudahkan proses belajar-mengajar, dalam rangka efektivitas komunikasi guru dan murid. 


\section{Sunan Gunung Jati, sang penegak Kesultanan Banten}

Pada awalnya, Banten adalah bagian dari Kerajaan Sunda. Sunan Gunung Jati datang dari Demak ke Banten, kemudian berhasil menaklukan kerajaan tersebut atas perintah Sultan Trenggana. Tujuannya, bukan hanya untuk memperluas wilayah Kerajaan Demak, meliankan juga untuk menyebarkan agama Islam di Pulau Jawa. Pada 1525, Sunan Gunung Jati tiba di Banten dan menyiarkan agama Islam. Walau tidak mudah dalam memperkenalkan dan mengajarkan Islam, tetapi dengan kesabaran dan kegigihannya. Banten berhasil diislmakan (Hayah, 2016: 3).

Pasukan bersenjata kerajaan Demak pertama-tama menyerang dan merebut Sunda Kelapa, penyerangan itu dipimpin oleh Sunan Gunung Jati yang diutus oleh Sultan Trenggana. Setelah berhasil direbut, kerajaan Demak menempatkan seorang raja beragama Islam di Banten, yaitu Sunan Gunung Jati. Menurut Djajadiningrat, kerajaan Banten didirikan oleh kesultanan Demak (dalam Guillot, 2008:15). Perjuangan Sunan Gunung Jati di atas dapat memberikan gambaran tentang sepak terjang Sunan Gunung Jati.

\section{Perancangan Karakter}

Kepribadian yang dibuat terisnpirasi dari film Sunan Gunung Jati, 1984 sebagai semangat perjuangan dan latar belakang hidup dari Jawa dan lama tinggal di Mekah, jiwa pemimpin yang dingin dan bersahaja. Sederhana dan tenang, namun cerdas dalam bertindak. Kuat dan menjunjung tinggi adat budaya.

Untuk memulai desain karakter Sunan Gunung Jaati, Peneliti memfokuskan pembahasannya pada elemen wajah, elemen tubuh, elemen aksesoris, elemen busana, dan elemen warna. Berikut pembahasannya.

1. Elemen wajah dibuat disesuaikan dengan wajah lelaki Indonesia yang berkhulit sawo matang, selain itu penambahan kumis sebagai ciri khas lelaki dengan usia dewasa.

2. Elemen tubuh, bentuk tubuh yang dibuat sebagai karakter dari Sunan Gunung Jati dibuat tidak terlalu tinggi ataupun pendek yang mencirikan orang asli dari Indonesia.

3. Elemen aksesoris, pemakaian aksesoris kepala untuk karakter tokoh Sunan Gunung Jati yang lama hidup di tanah Jawa yang kental dengan kain jarik sebagai hiasan kepala orang Jawa dahulu. Selain itu, adanya film, Sunan Gunung Jati, dibuat pada 1984 memperkuat literatur data visual pendukung untuk pembuatan karakter tokoh Sunan Gunung Jati.

4. Elemen busana, pemakaian busana yang diterapkan pada tokoh Sunan Gunung Jati yang telah lama tinggal di Mekah, dengan ciri khas pakaian langsung atau gamis, kemudian ditambahkan baju luar (outerwear) sebagai penambahan busana.

5. Elemen warna, pemakaian warna yang diterapkan adalah menggunakan warna-warna yang cerah dan warna yang sederhana, yang cendurung warna-warna dari warna primer. Ini dibuat dikarenakan warna cerah mewakili dari karakter anak-anak yang periang dan suka beraktivitas.

Sedangkan untuk media pembuatan karakter dibuat dengan sketsa manual dan diwarnai dengan menggunakan cat air. Cat air mempunyai karakteristik yang khas dibandingkan menggunakan pewarnaan digital. Tekstur yang dihasilkan begitu mudah dilihat, sederhana, apa adanya, dan mmbentuk gradasi yang tercipta antara cat dan air membentuk gradasi.

Gambar berikut adalah salah satu potongan film yang di ambil ketika Sunan Gunung Jati sedang berdiri sendiri. Kemudian oleh penulis diambil untuk dijadikan bentuk karakter baru dengan media gambar manual dengan menggunakan cat air. 


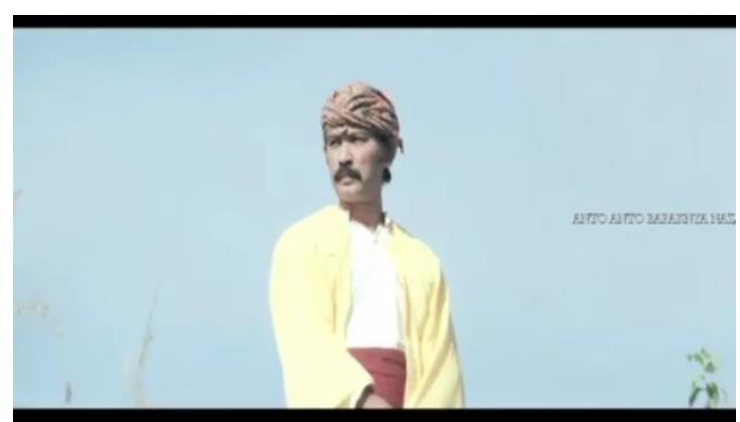

Gambar 1 Sunan Gunung Jati dalam Film, 1984 Sumber: http://youtu.be/cCilToopU0w, pada 15

September 2017.

\section{Proses sketsa}

Setelah menemukan data visual dari literatur yang ada, kemudian dilakukan proses pembuatan sketsa kasar dengan menggunakan pensil, yang nantinya akan diwarnai menggunakan cat air.

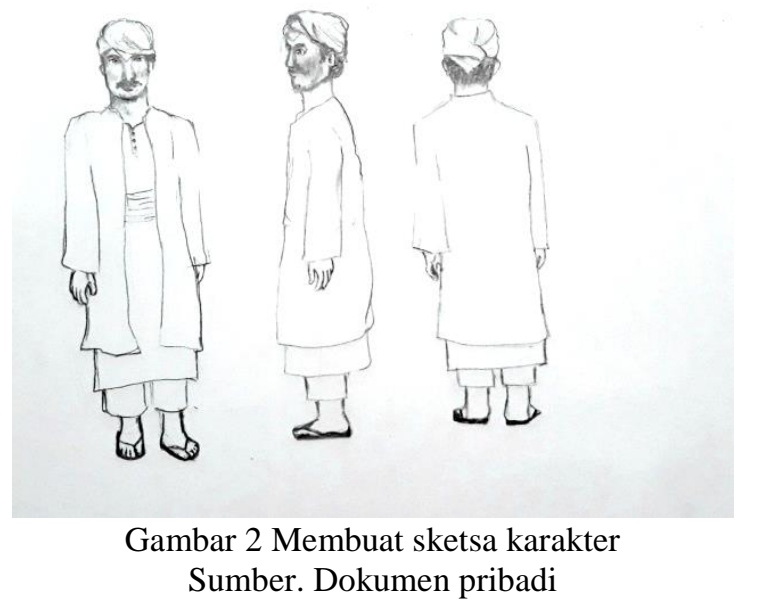

\section{Proses pewarnaan}

Proses pewanaan sebagai elemen tekstur menggukanan cat air. Dengan elemen warna yang dipilih adalah warna cerah dengan warna-warna primer, yaitu kuning, merah, putih, dan cokelat kekuningan. Warna kuning mencerminkan kedamaian, ketenangan yang mewakili dari karakter Sunan Gunung Jati, dan kuning sendiri biasa dipresentasikan sebagai warna emas atau kebangsawanan. Sedangkan warna merah pada kain di pinggang mengarah pada keberanian, dan putih yang lebih kepada suci atau bersih.

Elemen garis yang dibuat tegas, namun tidak terlalu kuat atau tebal, dimaksudkan agar ciri khas dari cat air lebih menonjol. Elemen bentuk dari wajah khas Indonesia atau pribumi, dengan penambahan kumis sebagai ciri khas orang yang sudah dewasa, dan postur tubuh yang seperti orang-orang Jawa pada umumnya, dengan proporsi tubuh tidak terlalu besar atau terlalu kurus.

Aksesori yang dikenakan oleh Sunan Gunung Jati tidak dibuat berlebihan karena dari segi tahun yang memungkinkan kehidupan di abad XV masih terbilang sangat sederhana di masa kerajaan Indonesia. Selain itu, dari beberapa sumber menjelaskan bahwa sosok Syarif Hidayatullah adalah seorang yang sederhana dan merakyat.

Pakaian yang dipakai sebagai ciri khasnya adalah penutup kepala dari kain jarik yang diikat dan menjari ciri khas kebudayaan tanah Jawa. Dengan pakaian langsung sebagai bagian 
dari pakaian khas Timur Tengah, di mana Sunan cukup lama berilmu di sana dengan mendapat gelar sultan.

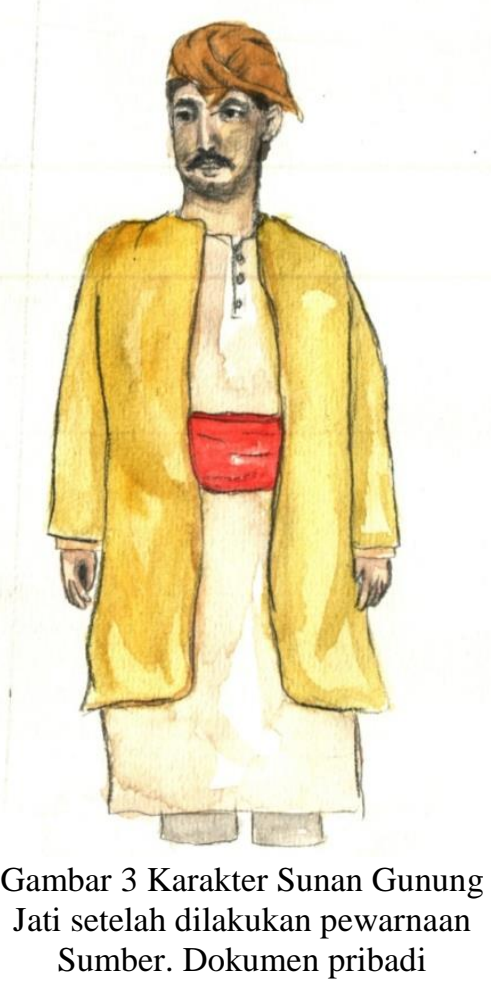

\section{SIMPULAN}

Berdasarkan penelitian di atas, dapat disimpulkan bahwa penelitian dalam proses perancangan ini sangat penting untuk menjadi pendukung dan landasan ide pesan yang ingin disampaikan, terutama dalam merepresentasikan tokoh bersejarah, Sunan Gunung Jati.

Tugas dari peneliti di sini adalah untuk mengaplikasikan informasi dan data yang telah dikumpulkan menjadi visual karakter untuk keperluan buku ilustrasi. Karya yang dihasilkan juga harus memiliki makna dan arti dan dapat dimengerti oleh target pembaca. Elemen desain dipakai untuk keperluan membuat karakter tokoh dalam sejarah Kesultanan Banten, yaitu Syarif Hidayatullah atau Sunan Gunung Jati di antaranya elemen wajah, tubuh, aksesori, busana, dan elemen warna. Penciptaan karakter Sunan Gunung Jati dimulai dengan melakukan observasi, kemudian dilanjutkan ke tahap mendesain karakter berdasarkan elemen desain, lalu menuju ke proses sketsa, proses perancangan, kemudian proses pewarnaan karakter Sunan Gunung Jati.

Sebagai penerus generasi Indonesia, haruslah mecintai budaya tanah air sendiri dan tidak melupakan sejarahnya. Melalui penciptaan tokoh karakter mengenai Kesultanan Banten ini, diharapkan generasi muda khususnya anak-anak menjadi tertarik untuk mengetahui lebih lanjut tentang bacaan sejarah. Penelitian ini memberi pesan melalui penciptaan karakter tentang perjuangan para sultan dalam memimpin, menyiarkan agama islam, dan membangun kerajaan sesuai dengan amal kebaikan ajaran agama. Selain itu, penelitian ini dapat memberikan gambaran mengenai karakter Sunan Gunung Jati. 


\section{DAFTAR PUSTAKA}

Achmad, S. W. (2017). Sejarah Islam Di Tanah Jawa. Yogyakarta: Araska.

Graaf, de H.J. dan Pigaud, Th. (1989). Kerajaan-Kerajaan Islam Di Jawa. Jakarta: Graffiti Pers, Anggota IKAPI.

Guillot, C. (2008). Banten Sejarah Dan Peradaban Abad X-XVII. Jakarta: Pusat Penelitian dan Pengembangan Arkeologi Nasional.

Hayah, A. (2016). Kebijakan Ekonomi Sultan Maulana Hasanuddin Di Kesultanan Banten Tahun 1526-1570 M. (Skripsi). Sejarah dan Kebudayaan Islam, UIN Sunan Kalijaga, Yogyakarta.

Anto, P., Andrijanto, M. S., dan Akbar, T. (2017). Perancangan Buku Pedoman Umum Ejaan Bahasa Indonesia Sebagai Media Pembelajaran Ejaan Di Sekolah. Jurnal Desain, 4(02), 92-99.

Pratama, D., Wardani, W. G. W., dan Akbar, T. (2017). Designing Visual Character Of Raden Wijaya As Historical Figure In Visual Novel. International Journal Of Scientific \& Technology Research, 6(11), 207-210.

Pratama, D., Wardani, W. G. W. dan Akbar, T. (2018). Designing Visual Novel Characters of Gajah Mada and Tribhuwana Tunggadewi As Representation of History Figures. Humanus, 17(1), 84-96. 